\title{
Condições de trabalho das/os assistentes sociais: precarização ética e técnica do exercício profissional
}

\author{
Working conditions of social workers: ethical and technical \\ precariousness of professional practice
}

\author{
Maria Teresa dos Santos* \\ Vania Maria Manfroi**
}

\begin{abstract}
Resumo: O presente artigo trata das condições de trabalho dos assistentes sociais, cuja precarização tem repercutido diretamente nas condições éticas e técnicas de seu exercício profissional. Para tanto, busca-se, na tradição marxista, os elementos para uma análise da problemática, em um esforço de partir do empírico para a discussão de possíveis tendências do real. A referência dos dados empíricos são as pesquisas realizadas sobre o mercado de trabalho dos assistentes sociais em Santa Catarina e no Espírito Santo nos anos de 2011 e 2007, respectivamente. A partir delas se problematiza o processo de precarização do trabalho e suas repercussões nas condições objetivas e subjetivas do trabalho desses profissionais. A condição para o enfrentamento da precarização do trabalho passa pela compreensão dos assistentes sociais como parte da classe trabalhadora, em um movimento oposto à individualização, como propõe o projeto neoliberal. Palavras-chave: condições de trabalho; serviço social; precarização.
\end{abstract}

\begin{abstract}
This article deals with the working conditions of social workers, which precariousness is reflected directly in the ethical and technical conditions of their professional practice. Therefore, we seek the elements for an analysis of the problem in the Marxist tradition, in an effort to discuss possible real trends from empirical evidence. The source of empirical data are researches on the labor market for social workers in the city of Santa Catarina and the state of Espírito Santo, in 2011 and 2007 respectively, from which it discusses the casualization process of work and its impact on objective and subjective conditions of the social worker practice. The condition to fight the casualization of labor involves understanding social workers as being part of the working class, in a movement opposing the individualization as proposed by the neoliberal project.

Keywords: working conditions; social work; casualization.
\end{abstract}

\footnotetext{
* Professora Associada I do Departamento de Serviço Social da Universidade Federal de Santa Catarina. Correspondência: DSS/CSE/UFSC: Campus Universitário João David Ferreira de Lima - Florianópolis-SC. CEP: 88040-900. Email:<maria.teresa.santos@ufsc.br>

** Professora Associada IV do Departamento de Serviço Social da Universidade Federal de Santa Catarina. Correspondência: DSS/CSE/UFSC: Campus Universitário João David Ferreira de Lima - Florianópolis-SC. CEP: 88040-900. Email:<vania.maria.manfroi@ufsc.br>
} 


\section{Introdução}

A partir do recorte de pesquisas desenvolvidas sobre o assistente social no mercado de trabalho, este artigo aborda quais são os principais desafios postos a esses profissionais face à precarização das condições éticas e técnicas do exercício da profissão, replicando o cenário do trabalho precarizado de uma forma geral, no Brasil e no mundo.

Acredita-se que o tema é pouco debatido na categoria e é, sem dúvida, necessário para a continuidade do amadurecimento teórico e prático da profissão. O ponto de partida teórico recolhe da tradição marxista os elementos para uma análise da problemática, em um esforço de partir do empírico não para simplesmente referendá-lo, mas para buscar as tendências reais.

Marx (2013) acena com uma reflexão sobre a apropriação do real no prefácio à primeira edição de $O$ capital, no qual diferencia os instrumentos de pesquisa, nas ciências naturais, do conhecimento sobre o real histórico, mediado pela forma-mercadoria.

[...] $\mathrm{Na}$ análise das formas econômicas não podemos nos servir de microscópio nem de reagentes químicos. A força da abstração [...] deve substituir-se a ambos. Para a sociedade burguesa, porém, a forma-mercadoria do produto do trabalho, ou a forma do valor da mercadoria, constitui a forma econômica celular. Para o leigo, a análise desse objeto parece se perder em vãs sutilezas. Trata-se com efeito de sutilezas, mas do mesmo tipo daquelas que interessam à anatomia micrológica (MARX, 2013, p. 78).

Portanto, na sociedade burguesa, a forma-mercadoria se impõe como elemento mediador do real e, assim, condiciona toda a organização social regida sob o capital. Como não é possível utilizar microscópios, a força da razão dialética é que permite desvendar as conexões da mercadoria no cotidiano da vida social. Isto significa que, no processo de conhecimento da sociedade burguesa, a razão dialética é aquela capaz de desmistificar o trabalho como expressão de uma mercadoria.

Importante complementar com a explicação de Harvey (2013, p. 21) sobre o método empregado por Marx em O capital: "O capitalismo não é nada se não estiver em movimento". Assim, o referido autor complementa que "o que Marx procura n'O Capital é um aparato conceitual, uma estrutura profunda que explique como o movimento se desenvolve concretamente no interior de um modo de produção capitalista"(HARVEY, 2013, p. 21).

Diante disso, o pressuposto central deste artigo é o de que o assistente social, sendo um profissional assalariado, vende sua força de trabalho, fato que o condiciona enquanto categoria que compõe a classe trabalhadora. No entanto, esse processo não é estático: é dialético, é histórico e depende do processo de desenvolvimento da luta de classes. Compreende-se que não se trata de um pressuposto abstrato, no sentido de ser uma mera concepção teórica, mas sim real e concreto, devendo ser analisado na realidade profissional. 


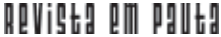

\{ CONDICÕES DE TRABALHO DAS/DOS ASSISTENTES SOCIAIS - SANTOS, M. T.; MANFROI, V. M. \} DOI: $10.12957 /$ rep.2015.21057

Marx (2013, p. 91) também afirma que "o concreto é síntese de múltiplas determinações", uma vez que, para ele, a dialética "apreende de forma desenvolvida no fluxo do movimento, portanto, incluindo o seu lado transitório; porque não se deixa intimidar por nada e é, por essência, crítica e revolucionária". Nesta perspectiva, é precondição que a sociedade capitalista seja entendida em sua forma transitória, pois "nas próprias classes dominantes já aponta o pressentimento de que a sociedade atual não é um cristal inalterável, mas um organismo capaz de transformação e em constante mudança" (MARX, 2013, p. 80).

Continuando, no prefácio à primeira edição de $O$ capital, Marx (2013, p. 80) aponta que os indivíduos estão inseridos nas relações sociais de produção, razão pela qual é fundamental entendê-los no seu processo de condicionamento:

Meu ponto de vista, que apreende o desenvolvimento da formação econômica da sociedade como um processo histórico-natural, pode menos do que qualquer outro responsabilizar o indivíduo por relações das quais ele continua a ser socialmente uma criatura, por mais que subjetivamente se possa colocar acima delas.

Por outro lado, ao entender que "a sociedade atual não é um cristal inalterável", Marx (2013, p. 80) compreende a luta de classes, capaz de alterar o modo de produção, enfatizando que, "na Inglaterra, o processo revolucionário é tangível. Quando atingir certo nível, haverá de repercutir no continente. Ali, há de assumir formas mais brutais ou mais humanas, conforme o grau de desenvolvimento da própria classe trabalhadora" (MARX, 2013, p. 79).

Pensar a profissão a partir dessa perspectiva, portanto, significa compreender os processos objetivos e subjetivos de determinado período histórico. Ou seja, sendo o assistente social um trabalhador que vende sua força de trabalho, ele se insere nas formas contemporâneas de exploração. E isso não é apenas uma "palavra de ordem" a ser repetida, mas sim uma questão central.

Aliados às condições objetivas do trabalho - baixos salários, contratações temporárias, precarização dos vínculos e das condições de trabalho - encontram-se, ainda, os aspectos subjetivos, quais sejam, as ideologias neoliberais, as concepções pós-modernas e neoconservadoras. São, muitas vezes, "o canto da sereia", que encanta os menos avisados e que impacta diretamente na forma de se compreender o real e, consequentemente, no agir do assistente social.

Assim, este artigo está organizado em três seções principais. Na primeira delas, sinteticamente, parte-se da reflexão acerca da compreensão sobre trabalho precário e o surgimento do "precariado", como substrato teórico para se analisar as condições de trabalho do assistente social. 


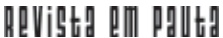

\} CONDIÇÕES DE TRABALHO DAS/DOS ASSISTENTES SOCIAIS - SANTOS, M. T.; MANFROI, V. M. \}

DOI: 10.12957/rep.2015.21057

Na segunda seção são discutidas as condições de trabalho dos assistentes sociais a partir de dados empíricos que retratam o processo de precarização, seja da condição de trabalho ou institucionais. Para tanto, são utilizadas, especialmente, referências de pesquisas desenvolvidas coletivamente e que tiveram participação de autores deste artigo, a saber: pesquisa Mercado de trabalho: formação e exercício profissional dos assistentes sociais de Santa Catarina (2011), e pesquisa Mercado de trabalho dos assistentes sociais no Espírito Santo (2007). A primeira com financiamento do Conselho Nacional de Desenvolvimento Científico e Pesquisa (CNPq) e a segunda financiada pelo Cress 17a․ região.

Em Santa Catarina, foram entrevistados 132 profissionais na Grande Florianópolis e, nas demais regiões, foram realizados seis grupos focais com a participação de 38 assistentes sociais, além de cinco entrevistas com profissionais de referência no estado, totalizando 175 sujeitos pesquisados. O universo da pesquisa no Espírito Santo, por sua vez, foi composto pelos assistentes sociais filiados ao Cress até novembro de 2006. Em virtude da grande concentração de assistentes sociais na Grande Vitória, optou-se por este universo e, ao final, foram pesquisados 202 profissionais.

Na terceira seção, por fim, a partir das mesmas pesquisas, são problematizadas as condições de trabalho e as repercussões na saúde e na subjetividade do assistente social.

\section{Trabalho precário e precarização na contemporaneidade}

Para a compreensão do processo de precarização do trabalho, é importante recuperar as reflexões de Antunes (1999; 2005) e Harvey (2003), que assinalam as principais mudanças que ocorreram no trabalho em nível mundial após os anos 1980. Tendo por base o toyotismo, são exemplos, como mudanças no capital, as novas formas de gestão intensivas e poupadoras de mão de obra, heterogeneização, fragmentação e complexificação da classe trabalhadora, produção conduzida pela demanda/estoque mínimo, pequeno número de trabalhadores multifuncionais, processo de trabalho intensificado, sindicalismo de envolvimento, desemprego estrutural e várias alternativas de trabalho e de geração de renda.

O trabalho precário é um fenômeno de abrangência mundial, mas que se configura de modo particular nos diferentes países, dependendo de características locais, conforme argumenta Kallenberg (2009, p. 21). Para o referido autor, trabalho precário significa "trabalho incerto, imprevisível, e no qual os riscos empregatícios são assumidos principalmente pelo trabalhador e não por seus empregadores ou pelo governo".

Pierre Bourdieu (1998), por sua vez, compreende que o processo de precarização do trabalho faz parte da estratégia neoliberal de se fazer cumprir um programa de destruição metódica de coletivos, no qual se 


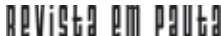

\} CONDIÇÕES DE TRABALHO DAS/DOS ASSISTENTES SOCIAIS - SANTOS, M. T.; MANFROI, V. M. DOI: $10.12957 /$ rep.2015.21057

busca lidar apenas com o indivíduo. Assim, pela política de desregulamentação financeira, são colocadas em risco as estruturas coletivas de resistência ao mercado, bem como os grupos de trabalho - com a individualização de salários e carreiras, os coletivos de defesa de trabalhadores e até mesmo a família, uma vez que o mercado se constitui por classes de idade. A insegurança em relação ao trabalho produz o que Bourdieu (1998, p. 140 grifo do autor) denomina de "exército de reserva de mão-de-obra-docilizada pela precarização e pela ameaça permanente do desemprego", configurando uma verdadeira "violência estrutural do desemprego, da precariedade e do medo inspirado pela ameaça de demissão [...]". Nesta direção, Dejours (2001, p. 51) cita alguns efeitos da precarização do trabalho, quais sejam:

[...] a intensificação do trabalho e o aumento do sofrimento subjetivo; [...] a neutralização da mobilização coletiva contra o sofrimento, contra a dominação e contra a alienação; [...]; a estratégia defensiva do silêncio, da cegueira e da surdez. Cada um deve antes de tudo se preocupar em "resistir". Quanto ao sofrimento alheio não só "não se pode fazer nada", como também sua própria percepção constitui um constrangimento ou uma dificuldade subjetiva suplementar, que prejudica os esforços de resistência; [...] o individualismo, o cada um por si.

A precarização do trabalho, desta forma, é um fenômeno importante na contemporaneidade e origina uma expressão que vem definir um novo segmento de classe: o precariado. O debate sobre o precariado surge na Europa logo após as crises sucessivas do sistema capitalista e as reformulações no padrão de proteção social. Standing $(2013$, p. 11) chama a atenção para a importância de se conhecer o precariado, pois "há um perigo de que seu aparecimento possa levar a sociedade para uma política de inferno". Ou seja, a necessidade de entender o precariado é urgente, pois, para o autor, trata-se da "nova classe perigosa". Standing ainda chama atenção para outro importante aspecto: o de que se trata de um fenômeno global.

O autor situa o surgimento do precariado nos anos 1970, no contexto ideológico do neoliberalismo, que apostou em políticas para "aumentar a flexibilidade do mercado de trabalho" (STANDING, 2013, p. 15). Essas políticas, desenvolvidas pelos mais diversos países, resultaram "em milhões de pessoas ao redor do mundo sem uma âncora de estabilidade". Em outras palavras, para Standing (2013), o precariado relaciona-se à instabilidade no mercado de trabalho. $\mathrm{O}$ autor também destaca o "despertar do precariado", que teve início, segundo ele, no Dia do Trabalho, em 2001, na cidade de Milão, quando aconteceu "uma marcha alternativa em tom de protesto".

De outra ponta, Castel (1999, p. 17) complementa dizendo que "o processo de degradação dos eixos que se constituíam nos pilares da sociedade salarial vem pondo em xeque modos de socialização e formas de integração com base no trabalho, vem revertendo identidades, filiações, 
formas de coesão e de solidariedade". O autor resgata o passado em seu livro intitulado As metamorfoses da questão social, no qual assinala que o trabalho é uma categoria central, mas não foi "um ponto de partida", pois o seu intento era "compreender a incerteza dos estatutos, a fragilidade do vínculo social, os itinerários cuja trajetória tremeu" (CASTEL, 1999, p. 23). O estudo de Castel buscava significar a "desconversão social, o individualismo negativo, a vulnerabilidade de massa, a desvantagem, a invalidação social, a desfiliação", os quais eram tratados como problemas de integração e de anomia.

Na mesma linha, Mattoso (apud BEHRING, 2003, p. 40) afirma que, após o advento da globalização e do neoliberalismo, o trabalho e o emprego passaram a apresentar, como característica, a insegurança no mercado de trabalho. Ou seja, não há mais, por parte dos Estados Nacionais, a prioridade do pleno emprego. Além disso, o autor apresenta as diversas inseguranças do mundo laboral contemporâneas, quais sejam: no emprego, com a redução da estabilidade e a subcontratação; na renda, com a flexibilização dos salários, a queda nos gastos sociais e fiscais das empresas, a deterioração da distribuição de renda, o crescimento da pobreza; na contratação do trabalho, com a expansão do dualismo no mercado e com o risco da ruptura jurídica do contrato; e na representação do trabalho, com "redução dos níveis e sindicalização".

Outro aspecto que se destaca no contexto atual diz respeito à criminalização da miséria e dos movimentos sociais. Conforme assinala Wacquant (2003, p. 72), essa criminalização é entendida "num sentido amplo de penalização da miséria, elaborada para administrar os efeitos das políticas neoliberais nos escalões mais baixos da estrutura social das sociedades avançadas". Além disso, acaba impactando nas condições de trabalho dos assistentes sociais, pois estes estão cada vez mais sendo chamados a atuar no controle social da vida das populações pauperizadas.

Wacquant (2003) identifica a pressão do capital transnacional sobre o alto escalão do Estado atuando na desregulamentação social e dos direitos, levando ao trabalho precário e ao "retorno de um velho estilo de Estado punitivo", baseado no neoliberalismo e em contraposição ao Estado de Bem-Estar Social. Isso significa que "a 'mão invisível' do mercado de trabalho precarizado conseguiu seu complemento institucional no 'punho de ferro' do Estado, que tem sido empregada para controlar a desordens geradas pela difusão da insegurança social" (WACQUANT, 2003, p. 73). Assim, a proteção social é substituída pela ação policial que atua de forma intrusiva "nas zonas inferiores do espaço social".

$\mathrm{O}$ autor desenvolve seus estudos comparando os contextos americano e europeu, especialmente o da França. Entretanto, no prefácio à edição brasileira do livro As prisões da miséria, faz uma reflexão pertinente acerca do contexto brasileiro: 


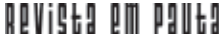

\} CONDIÇÕES DE TRABALHO DAS/DOS ASSISTENTES SOCIAIS - SANTOS, M. T.; MANFROI, V. M. \} DOI: $10.12957 /$ rep.2015.21057

A penalidade neoliberal é mais sedutora e funesta quando aplicada em países ao mesmo tempo atingidos por fortes desigualdades de condições e oportunidades de vida e desprovidos de tradição democrática e de instituições capazes de amortecer os choques causados pela mutação do trabalho e do indivíduo no limiar do novo século. (WACQUANT, 2011, p. 9).

Ou seja, no contexto brasileiro, entrelaçam-se os já conhecidos elementos históricos de desigualdade social, o processo frágil de democracia e o programa imposto pelo ajuste neoliberal. Assim, os efeitos desses ajustes tornam-se mais complexos e, ao mesmo tempo, seduzem parte da sociedade brasileira, como se viu recentemente no debate sobre a redução da maioridade penal, cuja aprovação pela Câmara dos Deputados ocorreu em 19 de agosto de 2015, em uma manobra de seu presidente'.

Entende-se que este contexto neoconservador, que resgata as alternativas penais, também impacta nas condições de trabalho dos assistentes sociais, uma vez que há certo consenso na sociedade para a retirada de direitos e para a reiteração de práticas punitivas. Esse novo consenso neoconservador está cada vez mais visível, especialmente no atual parlamento brasileiro. No entanto, embora os referidos autores tragam importantes contribuições, cabe dizer que não explicam as determinações sociais desse processo.

Já a análise crítica de Ruy Braga (2012, p. 17), por outro lado, afirma que a precarização "é constitutiva da relação salarial". Portanto, não é uma expressão da crise da "sociedade salarial", como afirma Castel (1999), e nem resultado das políticas neoliberais que impuseram a "flexibilidade do mercado de trabalho", como afirma Standing (2013).

Assim, segundo Braga (2012, p. 17), a precariedade é uma face do assalariamento, pois mesmo durante o pacto fordista apenas parte da população possuía um trabalho realmente protegido, ou seja, "[...] a fração profissional, branca, masculina, adulta e nacionalizada da classe trabaIhadora", ficando de fora parte do proletariado. O autor busca em Marx os fundamentos para explicar a existência da população excedente como inerente ao próprio capitalismo.

Outro autor que pode auxiliar na compreensão das determinações desse processo de precarização é Maranhão (2008), pois explica que os diversos Estados Nacionais, ao desenvolverem mecanismos de superação da crise, acirraram as contradições do sistema, gerando o desemprego de longa duração, o trabalho precário e a pobreza ampliada. No entanto, o mesmo autor entende que essas são alternativas inerentes ao atual padrão de acumulação capitalista mundializado e financeirizado, e funcionam como mecanismos de contratendência à lei geral da acumulação capitalista.

\footnotetext{
${ }^{1}$ Referência à proposta de emenda à Constituição no 171/93, que prevê a diminuição da maioridade penal de 18 para 16 anos nos casos de crimes hediondos. A presidência da Câmara dos Deputados é exercida pelo Deputado Federal
} 


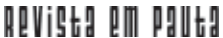

\} CONDIÇÕES DE TRABALHO DAS/DOS ASSISTENTES SOCIAIS - SANTOS, M. T.; MANFROI, V. M. \}

DOI: $10.12957 /$ rep.2015.21057

Maranhão (2008) ainda lembra que, para sair de uma visão abstrata da questão social, é necessário utilizar a Lei Geral da Acumulação Capitalista em "sua complexidade, seu caráter de corolário (necessário) ao desenvolvimento capitalista em todos os seus estágios" (NETTO apud MARANHÃO, 2008, p. 42). Portanto, desemprego e pauperização não são algo novo, pois são inerentes ao sistema do capital cuja centralidade é a exploração do trabalho e a apropriação privada da riqueza socialmente produzida.

O cenário de precarização, portanto, remete à necessidade de que se pense sobre as condições de trabalho do assistente social e sobre as repercussões nas suas condições de saúde e mesmo no próprio exercício profissional.

\section{Precarização das condições de trabalho dos assistentes sociais: dois estudos empíricos}

A atuação profissional do assistente social tem como referência mais importante o Código de Ética, conforme Resolução CFESS n. 273/93, que estabelece os princípios fundamentais, direitos e deveres, além de outros aspectos importantes dessa profissão. O art. 7ํㅡ, alínea "a", por exemplo, destaca que constitui direito do assistente social "dispor de condições de trabalho condignas, seja em entidade pública ou privada, de forma a garantir a qualidade do exercício profissional" (CONSELHO FEDERAL DE SERVIÇO SOCIAL, 1997, p. 25).

A Lei 8.662/93, que regulamenta a profissão, é outro importante instrumento normativo para a atuação do assistente social. Dentre outros aspectos, a referida lei prevê as competências e atribuições privativas do assistente social, as quais requerem condições mínimas de estrutura e de infraestrutura para serem plena e eficazmente desenvolvidas, devendo ser disponibilizadas no espaço sócio-ocupacional onde a ação profissional se desenvolve (CONSELHO FEDERAL DE SERVIÇO SOCIAL, 1997).

Com essa finalidade, o CFESS, por meio da Resolução 493/2006, que dispõe sobre as condições éticas e técnicas do exercício profissional do assistente social, definiu, em seu art. 1ํㅜ que "é condição essencial, portanto, obrigatória, para a realização e execução de qualquer atendimento ao usuário do Serviço Social a existência do espaço físico, nas condições que esta Resolução estabelecer" (CONSELHO FEDERAL DE SERVIÇO SOCIAL, 2006). Além disso, a mesma resolução prevê, no art. $3^{\circ}$, que "O atendimento efetuado pelo assistente social deve ser feito com portas fechadas, de forma a garantir o sigilo", o que reforça que as condições físicas do local de trabalho do assistente social são requisitos indispensáveis para o cumprimento da exigência ética do sigilo profissional.

Não obstante as legislações que dão sustentação jurídica ao exercício profissional, compreende-se que as condições efetivas para a atuação 


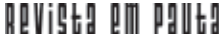

\} CONDIÇÕES DE TRABALHO DAS/DOS ASSISTENTES SOCIAIS - SANTOS, M. T.; MANFROI, V. M. \}

DOI: $10.12957 /$ rep.2015.21057

do assistente social ainda estão distantes dos padrões mínimos necessários, como demonstram os dados das pesquisas já mencionadas, aqui tomadas como referência empírica das reflexões.

Como o que está em discussão é a categoria específica dos assistentes sociais, que são majoritariamente contratados pelo Estado, deve-se compreender a precarização em um sentido mais amplo, tanto com relação às condições de acesso e inserção no mercado de trabalho protegido, quanto às condições de trabalho no espaço institucional propriamente dito. Assim, no caso do Serviço Social, uma mediação para que a precarização do trabalho seja entendida é a política social, na sua relação com o fundo público, pois o trabalho do assistente social está atravessado pelas determinações desta.

Segundo Evilásio Salvador (2010, p. 608), "o fundo público ocupa um papel relevante na articulação das políticas sociais e na sua relação com reprodução do capital. A presença dos fundos públicos na reprodução da força de trabalho e gastos sociais é uma questão estrutural do capitalismo". Nesta perspectiva, o orçamento da seguridade social continua perdendo recursos de suas fontes tributárias "exclusivas" devido à transferência de verbas para o orçamento fiscal por meio da Desvinculação das Receitas da União (DRU). A DRU transforma verbas destinadas ao financiamento da seguridade social em recursos fiscais para a composição do superávit primário e, por consequência, a sua utilização em pagamento de juros da dívida (SALVADOR, 2010). O fundo público, portanto, tem sido utilizado para viabilizar os interesses do capital financeiro.

Nas pesquisas sobre o mercado de trabalho dos assistentes sociais, no Espírito Santo (2007) e em Santa Catarina (2011), foram suscitadas diversas questões que relacionam a insuficiência da política às condições para o exercício profissional. Na pesquisa realizada em Santa Catarina, por exemplo, foi perguntado aos assistentes sociais se existiam problemas que dificultavam a realização de seu trabalho, ao que $73 \%$ responderam afirmativamente; $24 \%$ dos entrevistados disseram não haver dificuldades e 3\% não responderam. Dentre as dificuldades mais citadas, estão: a falta de estrutura física, de recursos humanos e materiais, de equipamentos e de veículos; equipe reduzida de profissionais; burocracia excessiva; problemas de gestão e financiamento; fragmentação da rede de proteção social; descontinuidade, fragmentação e sobrecarga de trabalho; e desconhecimento das atribuições do assistente social por outros profissionais e gestores.

Na pesquisa do Espírito Santo, solicitou-se que os profissionais citassem os cinco principais problemas relacionados às condições de trabalho. Dos 202 assistentes sociais entrevistados, 189 responderam à questão. Sintetizando os dados, verificou-se que foram mais citados os problemas relacionados à falta de recursos e de estrutura física, correspondendo a $49 \%$ das respostas. Além destes, os assistentes sociais também registraram como problemas a falta de reconhecimento, a falta de autonomia, o excesso 


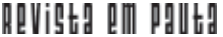

\} CONDIÇÕES DE TRABALHO DAS/DOS ASSISTENTES SOCIAIS - SANTOS, M. T.; MANFROI, V. M. \}

DOI: $10.12957 /$ rep.2015.21057

de demanda, a contratação precária, a descontinuidade das ações, a falta de capacitação, o excesso de carga horária, o desconhecimento sobre as atribuições do assistente social, além da periculosidade, da insalubridade e da falta de segurança no trabalho, bem como questões burocráticas.

$\mathrm{Na}$ análise das condições de trabalho do assistente social é importante ressaltar que, além da condição de trabalhador assalariado, este profissional está majoritariamente inserido no setor público. Portanto, na sua condição objetiva enquanto trabalhador, está imerso nos processos condicionantes das políticas sociais, na particularidade brasileira, ou seja, em um país periférico; assim, a forma de organização das políticas sociais neste momento do capitalismo afeta, de forma significativa, o exercício profissional do assistente social.

Em Santa Catarina, os profissionais destacaram alguns aspectos que retratam esta realidade, como as próprias condições estruturais, as quais dificultam ou mesmo impossibilitam o acesso da população à política como direito, reduzindo-o, por vezes, a uma benesse. Também foi citada a restrição da execução da política e, portanto, do trabalho do profissional, com a ausência ou a insuficiência de recursos financeiros e de espaço físico para o desenvolvimento das ações.

O depoimento de uma das assistentes sociais entrevistadas fala especialmente das dificuldades para atuação junto aos conselhos de direito, por conta da falta de investimento do governo, entre outros aspectos, conforme é possível observar:

Eu percebo então também um pouco dessa falta de condições de trabalho, assim, no sentido de que o governo tem que dar uma estrutura para esses conselhos funcionarem que também não fornece e a gente acaba assim assumindo muita coisa que não é nossa atribuição. $\mathrm{E}$ isso desgasta muito. É muito desgastante assim. E daí também reflete na nossa vida pessoal, porque daí tu leva trabalho pra casa. Tipo, agora vai assumir, a menina que tava na presidência do Conselho saiu, então eu assumi. Daí essa questão da responsabilidade com isso. Então acaba levando muita coisa pra fazer que não seria o meu papel enquanto conselheira, que é o papel do apoio que seria a Secretaria Executiva. E a Secretaria Executiva não dá conta, então a gente acaba fazendo pra que aconteça. Porque se tu ficar esperando, não acontece. Então pra ter um pouco de qualidade da coisa tu acaba fazendo o que não é tua atribuição. (Participante 31 - Santa Catarina).

Sintetizando, quando se fala de precarização em relação ao exercício profissional, é possível encontrar, em ambas as pesquisas, inúmeros dados convergentes, como, por exemplo, os baixos salários², as formas de vínculos precários, a focalização e a seletividade das políticas sociais, a falta de recursos financeiros e de infraestrutura para desenvolver o trabalho, a

${ }^{2}$ A questão salarial foi tratada anteriormente em Santos e Manfroi (2013). 


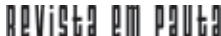

\} CONDIÇÕES DE TRABALHO DAS/DOS ASSISTENTES SOCIAIS - SANTOS, M. T.; MANFROI, V. M. DOI: $10.12957 /$ rep.2015.21057

ingerência política dos gestores no trabalho do assistente social, a falta de autonomia e de reconhecimento do trabalho, a fragmentação das políticas sociais, o adoecimento, o excesso de demanda, o remanejamento em função de perseguição política e a falta de espaço de trabalho adequado.

\section{Condições de trabalho, saúde e repercussões na subjetividade do assistente social}

Neste momento de capitalismo manipulatório e de neoconservadorismo, é central que se retome a radicalidade do projeto ético-político da profissão. No entanto, quando se pesquisa sobre o exercício profissional, percebe-se que há, muitas vezes, uma incompreensão desse projeto, que foi construído coletivamente, ou mesmo um certo reducionismo com relação a ele.

Quanto ao Código de Ética de 1993, em Santa Catarina foi perguntado aos profissionais se o conheciam, e $96 \%$ deles afirmaram que sim. Inquiriu-se, também, se as condições de trabalho permitiam uma atuação pertinente ao que está proposto no Código de Ética, especialmente com relação aos princípios lá previstos. Estes apontam para a necessidade de atuação crítica, de análise da realidade, de reconhecimento dos limites institucionais e das políticas sociais, bem como de aliança com a classe subalternizada. Os profissionais que afirmaram atuar de acordo com o Código de Ética somaram um percentual de $77,5 \%$; já aqueles que responderam atuar parcialmente, a partir do referido código, corresponderam a 29,2\%.

Quando se analisa as justificativas, observa-se que as respostas recorreram muito à Resolução 493/2006, pois um grande número de profissionais justifica a sua resposta, seja positiva, negativa ou parcial, referindose às instalações físicas e à infraestrutura (se preservavam ou não o sigilo), bem como à precarização das relações de trabalho e à autonomia profissional. Depreende-se, portanto, que há pouca problematização acerca dos princípios centrais do Código de Ética que aponta para discussões substantivas da profissão e que precisa ser mediatizada com os condicionantes do exercício profissional.

Destaca-se, aqui, um depoimento que problematiza a ética no cotidiano dos assistentes sociais quando diz que: "manter a ética é uma dura tarefa, 'andar na contra mão'" (questionário 711). Ou seja, para esse profissional, num contexto neoliberal, de retrocesso de direitos, o código está em contradição com as atuais tendências da sociedade. No Espírito Santo, a mesma questão foi perguntada e $57,9 \%$ dos profissionais responderam que as condições de trabalho permitem a atuação de acordo com o Código de Ética; já 22,7\% responderam que seu trabalho é pautado, em parte, no Código de Ética. Peixoto e Teixeira (2007, p. 57) constatam, pela análise das respostas dos profissionais, que "[...] os principais prejuízos pontuados pelos entrevistados para a atuação profissional com base no Có- 


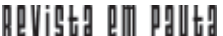

\} CONDIÇÕES DE TRABALHO DAS/DOS ASSISTENTES SOCIAIS - SANTOS, M. T.; MANFROI, V. M. \}

DOI: $10.12957 /$ rep.2015.21057

digo de Ética estão relacionados aos problemas na garantia do sigilo e a precariedade que não permitem desenvolver uma ação adequada".

Portanto, questiona-se até que ponto os profissionais têm problematizado, discutido e mediatizado os princípios do Código de Ética que assinalam valores sociocêntricos contrapostos ao pragmatismo e imediatismo do cotidiano profissional. Outro aspecto que se pode indagar é o de que, se o pragmatismo e o imediatismo não são superados por uma análise dialética da realidade, não se estaria correndo o risco de cair no neoconservadorismo, devido às próprias condições de trabalho? Barroco (2011, p. 212-213) relaciona o renascimento do conservadorismo com as novas condições de trabalho, e afirma que:

A reatualização do conservadorismo é favorecida pela precarização das condições de trabalho e da formação profissional, pela falta de preparo técnico e teórico, pela fragilização de uma consciência crítica e política, o que pode motivar a busca de respostas pragmáticas e irracionalistas, a incorporação de técnicas aparentemente úteis em um contexto fragmentário e imediatista. A categoria não está imune aos processos de alienação, à influência do medo social, à violência, em suas formas subjetivas e objetivas.

Giovanny Alves (2012, p. 98) complementa as análises sobre o impacto das transformações do trabalho sobre os trabalhadores, mostrando como essas transformações atingem a subjetividade do trabalhador:

É por mobilizar, com intensidade e profundidade, a alma humana que o novo capitalismo, com sua nova cultura da fluidez e precarização do trabalho e da vida social, contribui para a epidemia de novas doenças psicossomáticas. As doenças do novo capitalismo atingem mais o homem integral, sua mente e corpo, com o estresse e a depressão sendo sintomas da colonização intensa da vida social pelos requisitos empresariais.

Portanto, o processo de reorganização do capital cria a necessidade de novos valores para a legitimação ideológica das transformações. Surge, nesse contexto, o pensamento pós-moderno, que tem como características a revitalização do irracionalismo, a proliferação do individualismo e o ceticismo. Para Santos (2007, p. 37), "a impotência e a perplexidade diante do mundo contemporâneo são típicas atitudes dos pós-modernos". Segundo Josiane Santos (2007, p. 28-29), a consciência que correspondente à fase de acumulação flexível é "fugidia e efêmera; em meio à crescente insegurança provocada pelo desemprego, ela é marcada pela incerteza; do ritmo frenético das inovações lançadas no mercado, ela precisa ser cada vez mais descartável e capaz de assumir novidades". Em decorrência do processo de reorganização do capital, portanto, há a necessidade de novos valores para a legitimação ideológica das transformações. 


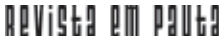

\} CONDIÇÕES DE TRABALHO DAS/DOS ASSISTENTES SOCIAIS - SANTOS, M. T.; MANFROI, V. M. \} DOI: $10.12957 /$ rep.2015.21057

As pesquisas sobre a realidade do mercado de trabalho dos assistentes sociais corroboram com a afirmativa anterior. Ao serem perguntados acerca da repercussão das condições de trabalho na sua saúde, as respostas dos profissionais entrevistados foram contundentes. No Espírito Santo (2007), de um total de 202 profissionais, 69\% afirmaram que o trabalho interfere em suas condições de saúde, ao passo que $28 \%$ disseram que não, e $3 \%$, não responderam.

O relatório da pesquisa aponta com mais detalhe esses dados: as principais questões mencionadas referem-se às doenças psicossomáticas, totalizando 110 casos; problemas físicos foram citados 34 vezes; e problemas referentes ao esforço mental e psicológico apareceram em um total de 20 casos registrados (CONSELHO REGIONAL DE SERVIÇO SOCIAL 17ª REGIÃO, 2007).

Já na pesquisa desenvolvida na Grande Florianópolis, de um universo de 132 profissionais, 79\% deles também responderam afirmativamente sobre a repercussão do trabalho em sua saúde. As respostas dos sujeitos pesquisados apontam uma predominância de problemas ligados às condições de trabalho que provocam estresse - a doença mais citada -, cansaço físico, dores e doenças cardiovasculares, entre outras. Além dessas, aparecem doenças de fundo subjetivo (angústia, desânimo, frustração), que estão, sem dúvida, ligadas ao excesso de trabalho.

De forma mais detalhada, o estresse foi o problema mais citado espontaneamente pelos profissionais, tendo aparecido 48 vezes, ou seja, o cotidiano no qual os profissionais estão inseridos não deixa de ser desgastante. Além disso, destaca-se que 18 profissionais citaram dores e problemas físicos e 15 mencionaram que a própria demanda é insalubre, podendo provocar doenças. Somando os que responderam que são afetados emocionalmente (15) e os que responderam apresentar sinais de ansiedade (13), chega-se a um número de 28 profissionais que apresentam esse tipo situação vinculada ao trabalho.

Alguns depoimentos dos sujeitos em Santa Catarina ilustram a questão do adoecimento no trabalho. Além das doenças e dos fatores subjetivos, os profissionais também apontaram as próprias condições de trabaIho, tais quais a carga horária elevada, o salário e as condições institucionais, dentre outras, como causadoras de problemas de saúde. Muito embora esses dados precisem ser analisados de forma mais profunda, verifica-se que eles reforçam que as condições de trabalho dos assistentes sociais têm sofrido o impacto do processo de reestruturação do trabalho, bem como das modificações que ocorreram no Estado, conforme já mencionado.

Quando se discutiu, nos grupos focais em Santa Catarina, sobre as condições de trabalho, vários aspectos relacionados à saúde dos profissionais também foram abordados, com destaque àqueles relativos ao desgaste físico e mental no cotidiano do trabalho do assistente social. 
A nossa atividade é muito desgastante, eu me sinto, [...] tem dias que eu chego em casa, assim, sem energia nenhuma. Eu já aprendi a não levar o problema em si pra casa. Mas eu sinto que eu chego em casa e eu não tenho energia. É isso assim, eu chego, tomo um banho, como alguma coisa, me jogo no sofá e apago. E aí a gente tá buscando assim, eu busquei uma forma de me cuidar, cuidar da minha saúde mental, assim, eu corro. [...] eu faço atividade física constante, porque eu preciso me cuidar. Eu já tive problema de tireoide, já apareceu um monte de caroço pelo corpo, e tal. Fiz tratamento [...] (Participante 6 - Santa Catarina).

Dentre os pontos em comum encontrados nos grupos focais, está o reconhecimento profissional. Muitos assinalaram a falta de reconhecimento profissional como um dos fatores que interferem na questão salarial. Isso fica evidente no depoimento que segue:

Isso, o reconhecimento? Hoje não tem um reconhecimento bastante interessante em nível de coordenação, Diretoria zero, Secretaria zero. $\mathrm{E}$ a gente vai buscando mesmo os espaços que você se põe na frente, que você questiona que você debate. [...] Mas hoje o meu trabalho não permite, mas posso te dizer que é vergonhoso você dizer que você é assistente social [...]. (Participante 23 Santa Catarina).

A questão do reconhecimento é apontada por Dejours (2001, p. 34) como uma das causas de sofrimento no trabalho. Para o autor, "quando a qualidade de meu trabalho é reconhecida, também meus esforços, minhas angústias, minhas dúvidas, minhas decepções, meus desânimos adquirem sentido". Assim, quando o trabalho não é reconhecido, perde seu significado como algo que pode transformar o sofrimento em prazer. Desta forma, "o reconhecimento não é uma reivindicação secundária dos que trabalham. Muito pelo contrário, mostra-se decisivo na dinâmica da mobilização subjetiva da inteligência e da personalidade no trabalho" (DEJOURS, 2001, p. 34).

Percebe-se, portanto, que as condições objetivas de trabalho incidem diretamente na subjetividade do trabalhador. Na verdade, essas diferentes dimensões compõem uma totalidade, uma relação orgânica que não pode ser compreendida separadamente. Deste modo, quando se fala em precarização do trabalho, está se falando na precarização das condições de vida e da própria reprodução da vida do trabalhador.

\section{Considerações finais}

As reflexões aqui desenvolvidas apontam para um cenário complexo, multifacetado e desafiador às condições materiais e subjetivas do trabalho do assistente social. As pesquisas realizadas em Santa Catarina e 


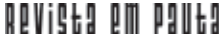

\} CONDIÇÕES DE TRABALHO DAS/DOS ASSISTENTES SOCIAIS - SANTOS, M. T.; MANFROI, V. M. \}

DOI: $10.12957 /$ rep.2015.21057

no Espírito Santo sobre o mercado de trabalho desses profissionais, bem como sobre as condições para a sua efetivação, confirmaram que o panorama mais amplo, extremamente precário, dos trabalhadores, não é diferente nessa categoria profissional.

O exercício profissional do assistente social, portanto, está determinado por sua condição de trabalhador inserido na reestruturação dos processos de trabalho, que resultam em contratações temporárias, terceirização, baixos salários, ausência de autonomia e reconhecimento profissional, e falta de condições de execução do trabalho no setor público. Neste sentido, a falta de financiamento das políticas sociais brasileiras impacta diretamente o trabalho do assistente social no país, espaço privilegiado de atuação deste profissional.

Paradoxalmente, pode-se inferir, a partir dos dados das pesquisas realizadas, a frágil percepção das determinações sociais e econômicas mais amplas por parte dos assistentes sociais, apesar de serem elas que condicionam seu exercício profissional. Em decorrência deste fato, percebe-se também como débil a atuação política mais abrangente dos profissionais de base da categoria.

Tendo em vista o quadro estrutural exposto e os depoimentos coletados nas pesquisas, é importante destacar que o cotidiano profissional no qual está inserido o assistente social tem lhe apresentado diversos desafios, que refletem desde a sua condição de trabalhador à falta de reconhecimento da profissão e o lugar subalternizado que ocupa na divisão sociotécnica do trabalho, tema a ser aprofundado em outros estudos. Ora, essas constatações não podem ser relegadas a um segundo plano, se forem considerados os impactos diretos que têm na desvalorização do salário, em um cenário de "crise", de reorganização do capital e de mais restrições aos direitos dos trabalhadores.

É preciso, ainda, perceber um forte movimento do capital para a conformação ideológica e a construção do consenso de que o sistema capitalista é perene e eterno.

Num cenário tão difícil, pergunta-se: o que fazer?

Acredita-se que os dados empíricos revelados pelas pesquisas realizadas evidenciam a premência do investimento em novas pesquisas sobre o trabalho do assistente social, as quais contemplam desde as condições para o exercício profissional até a forma como essa atuação vem se desenvolvendo. É preciso construir uma ampla base de dados da profissão no Brasil, em períodos contínuos que subsidiem análises mais aprofundadas, bem como instrumentalizem as lutas da categoria. Mais do que constatar o avanço do neoconservadorismo na atuação profissional, é importante compreender como isso ocorre e em que extensão, de modo a se criar mecanismos de luta contra possíveis retrocessos da profissão.

Reforça-se o papel relevante das entidades representativas e organizativas dos assistentes sociais na construção estratégica da luta contra a 
precarização da formação e do exercício profissional, quais sejam: o Conselho Federal de Serviço Social/CFESS e os Conselhos Regionais de Serviço Social (Cress); a Associação Brasileira de Ensino e Pesquisa em Serviço Social (Abepss) e a Executiva Nacional de Estudantes de Serviço Social (Enesso). A construção de normativas que regulam as condições para o exercício da profissão constitui verdadeiro avanço na afirmação dos direitos profissionais mas, por si só, não responde às condicionantes estruturais que limitam a atuação profissional, repercutindo na ausência de condições éticas e técnicas, bem como na saúde do trabalhador.

A condição para o enfrentamento da precarização do trabalho passa pela compreensão, por parte dos próprios assistentes sociais, de que são parte da classe trabalhadora, em um movimento oposto à individualização, como propõe o projeto do capital. Para além dos desafios profissionais em si, é central a compreensão de que a profissão de assistente social está mergulhada nas contradições da sociedade capitalista e de que o cenário atual só reforça que as contradições inerentes a esse sistema estão se adensando e aprofundando. Os limites do seu desenvolvimento estão se tornando cada vez mais visíveis e, ao mesmo tempo, mais encobertos. Estão visíveis, conforme apontado, nas condições de trabalho cada vez mais precárias dos assistentes sociais, no adoecimento profissional e, sobretudo, nas novas formas de mistificação da realidade.

Assim, ao inquirir os assistentes sociais acerca da sua realidade, percebe-se uma análise imediata, pragmática, fatalista e pouco estratégica para enfrentar os condicionantes do exercício profissional, sem alianças de classe que possam ampliar a possibilidade de tensionamento, tanto das condições do exercício profissional, quanto das respostas que os profissionais têm formulado para as demandas e necessidades sociais dos usuários, pertencentes à classe dos expropriados pelo capital.

$\mathrm{Na}$ análise aqui realizada, as apreensões conservadoras e pósmodernas ajudam a obscurecer a realidade, pois, ao operarem a partir do micro, do risco, da vulnerabilidade, não permitem aos profissionais alçarem a análise dos processos singulares imersos na totalidade social capitalista. Assim, questões que Marx já apontava em O capital como sendo inerentes ao capitalismo, hoje são analisadas como novidades que surgiram após a falência do Estado de Bem-Estar Social. Portanto, a precariedade das condições de trabalho dos assistentes sociais não é novidade de um novo regime de acumulação, mas sim a face mais visível das reais contradições do capitalismo.

Desta forma, o assistente social reconhecer-se como classe é elemento fundante da superação da análise singular e superficial da sua condição de trabalhador. 


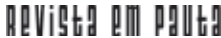

\} CONDIÇÕES DE TRABALHO DAS/DOS ASSISTENTES SOCIAIS - SANTOS, M. T.; MANFROI, V. M. \} DOI: $10.12957 /$ rep.2015.21057

\section{Referências}

ALVES, G. A "captura" da subjetividade. In: Trabalho e subjetividade: o espírito do toyotismo na era do capitalismo manipulatório. São Paulo: Boitempo. 2012.

ANTUNES, R. Adeus ao trabalho? Ensaio sobre as metamorfoses e a centralidade do mundo do trabalho. São Paulo: Cortez. 1999.

. Os sentidos do trabalho: ensaio sobre a afirmação e a negação do trabalho. São Paulo: Boitempo. 2005.

BARROCO, M. L. Barbárie e neoconservadorismo: os desafios do projeto ético-político. Serv. Soc. Soc., São Paulo, n. 106, abr./jun. 2011. Disponível em: <http://www.scielo.br/pdf/sssoc/n106/n106a02.pdf. > Acesso em: 23 jul. 2015.

BEHRING, E. R. Brasil em contrarreforma: desestruturação do Estado e perda de direitos. São Paulo: Cortez. 2003.

BOURDIEU, P. O neoliberalismo, utopia (em vias de realização) de uma exploração sem limites. In: Contrafogos: táticas para enfrentar a invasão neoliberal. Rio de Janeiro: Jorge Zahar Ed. 1998.

BRAGA, R. A política do precariado: do populismo à hegemonia lulista. São Paulo: Boitempo. 2012.

CASTEL, R. Metamorfoses da questão social: uma crônica do salário. Petrópolis: Vozes. 1999.

CONSELHO FEDERAL DE SERVIÇO SOCIAL. Código de Ética do Assistente Social. Lei 8662/93 de regulamentação da profissão. Brasília: Conselho Federal de Serviço Social. 1997.

. Resolução no 493/2006, de 21 de agosto de 2006. Dispõe sobre as condições éticas e técnicas do exercício profissional do assistente social. Disponível em: <http://www.cfess.org.br/arquivos/Resolucao_493-06.pdf>. Acesso em: 25 jul. 2015.

CONSELHO REGIONAL DE SERVIÇO SOCIAL 17ª Região. Relatório Pesquisa o mercado de trabalho dos assistentes sociais no Espírito Santo. Vitória (ES). 2007.

DEJOURS, C. A banalização da injustiça social. Rio de Janeiro: Editora FGV. 2001.

DELGADO, L. B.; LIMA, M. L.; CORRÊA, R. F. R. Mercado e condições de trabalho do assistente social: síntese da produção teórica no Brasil. In: II Colóquio Nacional sobre o Trabalho do assistente social. 2013. Disponível em: <http://coloquionacionalufal.blogspot.com.br/2013/07/trabalhos-queserao-apresentados-em_22.html.>. Acesso em: 25 jul. 2015. 


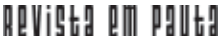

\} CONDIÇÕES DE TRABALHO DAS/DOS ASSISTENTES SOCIAIS - SANTOS, M. T.; MANFROI, V. M. \}

DOI: $10.12957 /$ rep.2015.21057

HARVEY, D. Condição pós moderna. São Paulo: Loyola. 2003.

. Para entender o capital. São Paulo: Boitempo. 2013.

KALLENBERG, A. L. O crescimento do trabalho precário: um desafio global. Rev. bras. Ci. Soc. [online], vol. 24, n. 69. 2009. Disponível em: <http:// www.scielo.br/pdf/rbcsoc/v24n69/02.pdf.>. Acesso em: 24 jul. 2015.

MANFROI, V. M. et al. A realidade profissional dos assistentes sociais de Santa Catarina: mercado de trabalho, exercício e formação profissional. Relatório de pesquisa. Florianópolis: Universidade Federal de Santa Catarina. 2011.

MARANHÃO, C. H. Capital e superpopulação relativa: em busca das raízes contemporâneas do desemprego e do pauperismo. In: BEHRING, E. R.; ALMEIDA, M. H. T. Trabalho e seguridade: percursos e dilemas. São Paulo/ Rio de Janeiro: Cortez/Uerj. 2008.

MARX, K. Prefácio à primeira edição. In: O capital. Livro I. São Paulo: Boitempo. 2013.

NOTÍCIAS CÂMARA. Câmara aprova em $2^{\circ}$ turno redução da maioridade penal em crimes graves. Disponível em: <http://www2.camara.leg.br/camara noticias/noticias/DIREITO-E-JUSTICA/494248-CAMARA-APROVA-EM-2TURNO-REDUCAO-DA-MAIORIDADE-PENAL-EM-CRIMES-GRAVES. html>. Acesso em: 22 nov. 2015.

PEIXOTO, P. E.; TEIXEIRA, R. V. Condições e relações de trabalho. In: CRESS 17a Região. Relatório Pesquisa o mercado de trabalho dos assistentes sociais no Espírito Santo. Vitória (ES). 2007.

SALVADOR, E. Fundo público e políticas sociais na crise do capitalismo. Serv. Soc. Soc., São Paulo, n. 104, out./dez. 2010. Disponível em: <http:/ /www.scielo.br/scielo.php?script=sci_arttext\&pid=S0101-662820100004 00002.>. Acesso em: 24 jul. 2015.

SANTOS, J. S. Neoconservadorismo pós-moderno e Serviço Social brasileiro. São Paulo: Cortez. 2007.

SANTOS, M. T.; MANFROI, V. M. Expansão e precarização: o mercado de trabalho dos assistentes sociais de Santa Catarina. Revista Em Pauta, v. 10. 2013.

STANDING, G. O precariado: a nova classe perigosa. Belo Horizonte: Autêntica. 2013.

WACQUANT, L. A penalização da miséria e o avanço do neoliberalismo. In: SANTANA, M. A.; RAMALHO, J. R. (org.). Além da fábrica: trabalhadores, sindicatos e nova questão social. São Paulo: Boitempo. 2003.

Nota aos leitores brasileiros: rumo a uma ditadura sobre os pobres? In: As prisões da miséria. Rio de Janeiro: Zahar. 2011. 


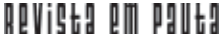

\} CONDIÇÕES DE TRABALHO DAS/DOS ASSISTENTES SOCIAIS - SANTOS, M. T.; MANFROI, V. M. \}

DOI: $10.12957 /$ rep.2015.21057

Recebido em 30 de julho de 2015.

Aprovado para publicação em 17 de outubro de 2015.

DOI: $10.12957 /$ rep.2015.21057

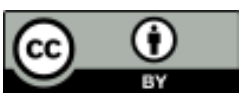

A Revista Em Pauta: Teoria Social e Realidade Contemporânea está licenciada com uma Licença Creative Commons Atribuição 4.0 Internacional.

EM PAUTA, Rio de Janeiro - 20 Semestre de 2015- n. 36, v. 13, p. 178 - 196 